\title{
COVID-19 Spread Faster with Air-Conditioning-Systems
}

\author{
Contributor: Maher Al-baghdadi ${ }^{1}$ \\ 1, Kufa Centre for Advanced Simulation in Engineering (KCASE), Department of Mechanical \\ Engineering, Faculty of Engineering, University of Kufa, Iraq.; mahirar.albaghdadi@uokufa.edu.iq
}

Version received: 16 August 2020

check for updates

\section{Definition}

Droplets and aerosolized viral particles expelling from the body through coughing or sneezing and it is spreading to nearby surroundings. CFD model has been developed to simulate the air flow and the transport and dispersion of the aerosolized viral particles and fine droplets suspended in the air particles through the office. The study presents two cases involving the spreading limits and pathways of the aerosolized viral particles and fine droplets suspended in the air in a place; without and with air conditioning unit. The results showed that the use of air conditioning systems can increase the chances of spreading COVID-19 virus infection. The air-conditioning unit recirculates the same air inside a room, and this has the potential to create a virus-laden environment. Air circulation indoors such as using air conditioning units should be avoided in closed places. Existing ventilation systems should be expanded to include extraction and air filtration systems and/or germicidal, ultraviolet light. Also, opening a window can help bring in fresh air from the outside and disperse stale air inside, and that could help reduce the possibility of the spread of the virus particles in the closed place. Lastly, crowds of people in closed public places should be avoided.

Table of Contents [Hide]

\section{Abstract}

Two-phases, three-dimensional, Computational Fluid Dynamics (CFD) model using Reynolds Average Navier Stokes (RANS) equations has been developed to simulate the air flow and the transport and dispersion of the aerosolized viral particles and fine droplets suspended in the air particles through the office. The study presents two cases involving the spreading limits and pathways of the aerosolized viral particles and fine droplets suspended in the air in a place; without and with air conditioning unit. The results showed that the use of air conditioning systems can increase the chances of spreading COVID-19 virus infection. The air-conditioning unit recirculates the same air inside a room, and this has the potential to create a virus-laden environment.

\section{COVID-19 Spread Faster with Air Conditioning Systems}

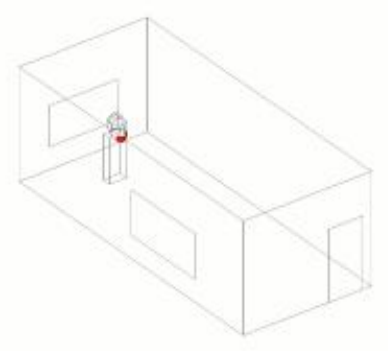

Without air conditioning system

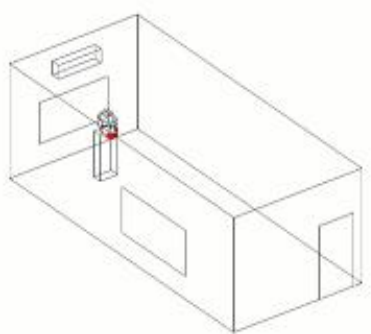

With air conditioning system 


\section{Background}

First, it's important to understand that the virus that causes COVID-19 is primarily spread through droplets when an infected person coughs or sneezes, according to the World Health Organization (WHO). The agency said that as a precaution, you should ensure "appropriate ventilation to reduce the risk of propelling droplets between spaces, especially from an infected person's space to that of others." "The use of fans and single air conditioning units in an indoor space where the space is shared by multiple people could, potentially, facilitate the dispersion of infected droplets," it said. That means that if someone who has the virus coughs or sneezes, and there's a fan in the room, the fan could potentially spread droplets further than they'd normally go [1].

According to the information available so far, the main way to transmit the Covid 19 virus between humans is through the human body's respiratory system absorption of liquid granules containing the virus. These liquid granules are produced by breathing, coughing, sneezing and speaking, and based on their size; it is possible to differentiate between being drops or atmospheric dust. The size of the droplet particles is one of the main factors that determine how the virus is transmitted. Are the particles large enough to be pulled down by the force of gravity? Or is it small enough for air to carry? [2].

The researchers found that wearing a cotton mask to cover the mouth and nose results in the droplets reaching only a meter and a half when sneezing [2], [3] . If a person does not wear a mask while sneezing, the spray can spread beyond two and a half meters within one second. It can even reach a maximum distance of about eight meters, according to the movement of air surrounding the person [2], [3],4]. The researchers recommended that a mask should be worn inside closed rooms, stressing that "even the simplest covers for the mouth and nose can provide basic protection in the event that there is more than one person in one room." [5],6], [7], [8].

\section{Airborne Transmission of COVID-19}

Aerosols are the smallest suspended particles and droplets in the air, which are smaller than five micrometers. When breathing out, speaking, or laughing, this fine mist spreads throughout the room. The larger droplets quickly fall to the ground, but the finest particles can remain suspended in the air for hours - especially in closed rooms. If an infected person stays in such a closed room, he can infect many others in a very short time - without ever having direct contact with them. But the worst-case scenario could happen with an air conditioning system in the room, which spreads the virus throughout the room within seconds, while keeping the windows closed [9].

Many scientists have found that the virus spreads, not only through a droplet-borne infection and direct contact, but also that it can spread by small particles over long distances in the air. However, scientists have not been able to actually conclude this theory and all that has been proven is that parts of the viral DNA are bound to these small particles $[10]$.

Other laboratory studies suggest that aerosols of SARS-CoV-2 remain infectious for longer than do aerosols of some related respiratory viruses. When researchers created aerosols of the new coronavirus, the aerosols remained infectious for at least 16 hours, and had greater infectivity than did those of the coronaviruses SARS-CoV and MERSCoV, which cause severe acute respiratory syndrome and Middle East respiratory syndrome, respectively [11],12]. Experiments done for aerosolized severe acute respiratory syndrome coronavirus 2 and determined that its dynamic aerosol efficiency surpassed those of severe acute respiratory syndrome coronavirus and Middle East respiratory syndrome. Although they performed experiment only once across several laboratories, they findings suggest retained infectivity and virion integrity for up to 16 hours in respirable-sized aerosols ${ }^{12]}$.

Many researchers reached the conclusion that the live, whole viruses of Corona can stick to an aerosol, which also makes the air contagious [10], [13]. A study conducted on patients with COVID-19 disease concluded that air samples taken at a distance of two to five meters from Corona patients in a hospital, despite the large distance, contain the Covid-19 virus in the air samples $[10]$. The study added that samples taken directly from the air were identical to the genome of these sick people.

A group of 239 researchers has called for an update of COVID-19 guidelines, as transmission via ultra-fine suspended 
matter in the air was not sufficiently taken into account ${ }^{[14]}$. Now the WHO also sees the danger[9].

\section{CFD Modeling and Analysis}

Computational Fluid Dynamics (CFD) is the sciences of predicting fluid flow, heat transfer, mass transfer, phase change, chemical reaction, mechanical movement, stress or deformation of related solid structures, and related phenomena by solving the mathematical equations that govern these processes using a numerical algorithm on a computer. The results of CFD are relevant in: conceptual studies of new designs, detailed product development, troubleshooting, and redesign. CFD complements testing and experimentation, by reduces the total effort required in the experiment design and data acquisition. CFD complements physical modeling and other experimental techniques by providing a detailed look into our engineering problems, including complex physical processes such as turbulence, chemical reactions, heat and mass transfer, and multiphase flows. Simulations can readily be done of physical phenomena that are difficult to measure, for example, full scale situations, environmental effects and hazards. In many cases, we can build and analyze virtual models at a fraction of the time and cost of physical modeling. This allows us to investigate more design options and "what if" scenarios than ever before. Moreover, flow modeling provides insights into our fluid flow problems that would be too costly or simply prohibitive by experimental techniques alone. The added insight and understanding gained from flow modeling gives us confidence in our design proposals, avoiding the added costs of over-sizing and over-specification, while reducing risk [15], [16].

There are many advantages in considering CFD. Firstly, the theoretical development of the computational sciences focuses on the construction and solution of the governing equations and the study of various approximations to these equations. CFD presents the perfect opportunity to study specific terms in the governing equations in a more detailed fashion. New paths of theoretical development are realized, which could not have been possible without the introduction of this branch of computational approach. Secondly, CFD complements experimental and analytical approaches by providing an alternative cost-effective means of simulating real-life system. Particularly, CFD substantially reduces lead times and costs in designs and production compared to experimental-based approach and offers the ability to solve a range of complicated problems where the analytical approach is lacking. These advantages are realized through the increasing performance power in computer hardware and its declining costs. Thirdly, CFD has the capacity of simulating flow conditions that are not reproducible in experimental tests found in geophysical and biological fluid dynamics, such as particles spread scenarios, nuclear accident scenarios, or scenarios that are too huge or too remote to be simulated experimentally (e.g., Indonesian Tsunami of 2004). Fourthly, CFD can provide rather detailed, visualized, and comprehensive information when compared to analytical and experimental fluid dynamics. Actually, one of the main advantages of CFD is that the user has an almost unlimited choice of the level of detail of the results $[15], 16]$.

Three dimensional, Two-phases, Computational Fluid Dynamics (CFD) model using Reynolds Average Navier Stokes (RANS) equations has been developed to simulate the air flow and the transport and dispersion of the aerosolized viral particles and fine droplets suspended in the air particles through the office.

Figures 1 and 2 show the air movement in a place for two cases; without and with air conditioning unit. The results illustrate the role that the air conditioning unit plays. Unlike when you open a window and allow air to pass through, air-conditioning unit recirculates the same air inside a room. 


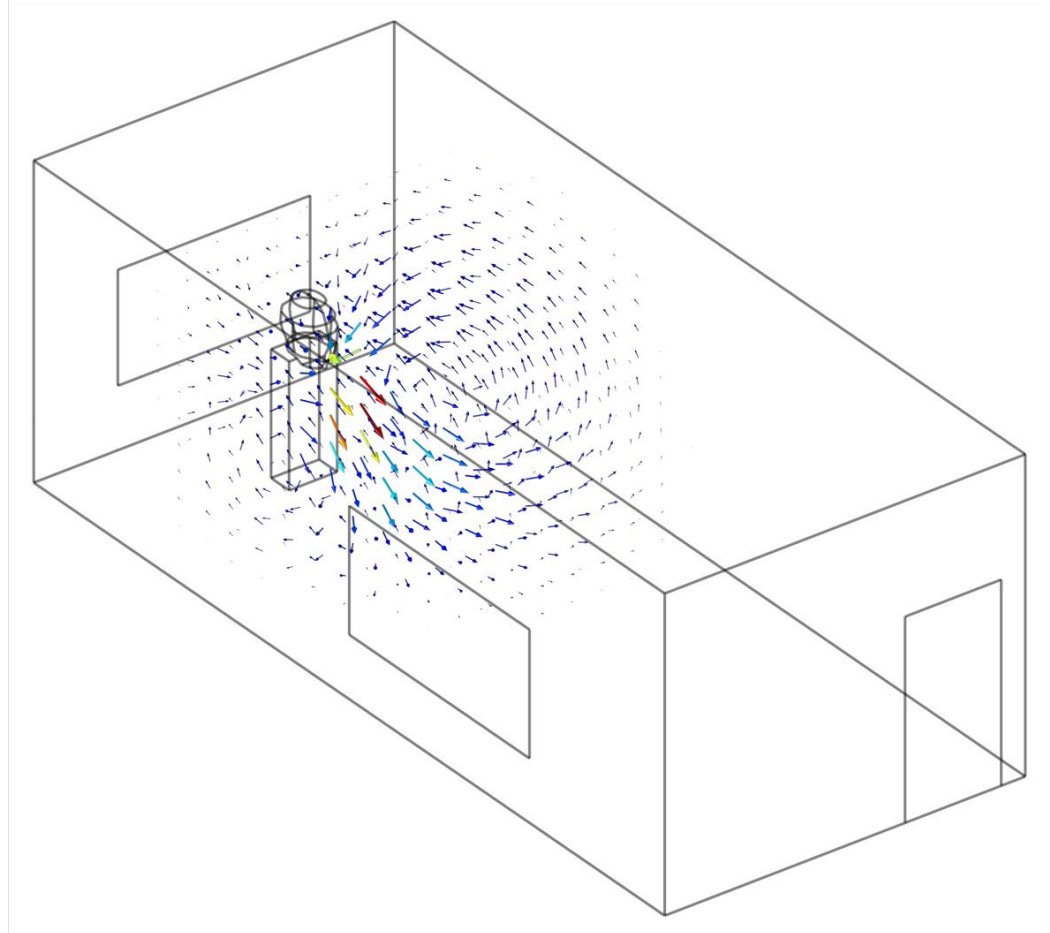

Figure 1. Air movement in a place without air conditioning unit.

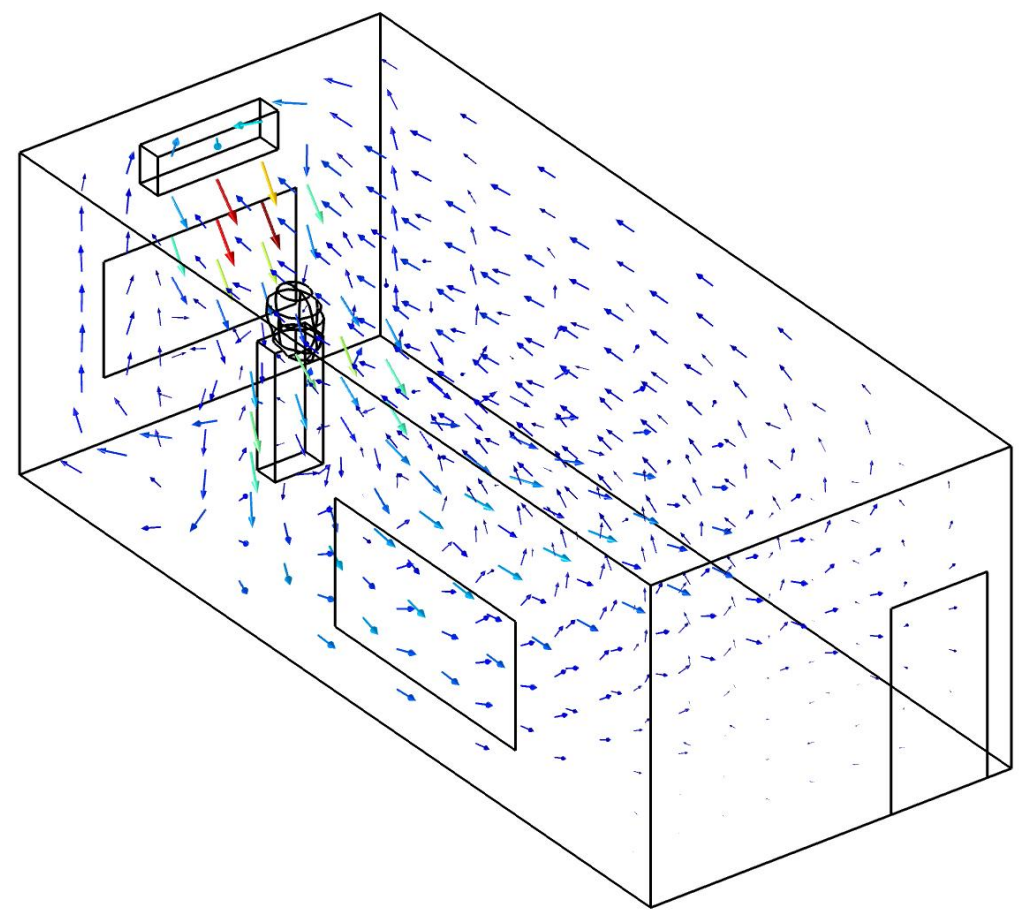

Figure 2. Air movement in a place with air conditioning unit.

Droplets and aerosolized viral particles expelling from the body through coughing or sneezing and it is spreading to nearby surroundings. Once a virus is hanging in the air, and as we know that the coronavirus can linger for hours, it will travel with air currents and this would the potential to create a virus-laden environment. Spreading limits and pathways of the aerosolized viral particles and fine droplets suspended in the air in case when the person is in a place for two cases, without and with air conditioning unit, are shown in Figures 3 and 4 respectively. 


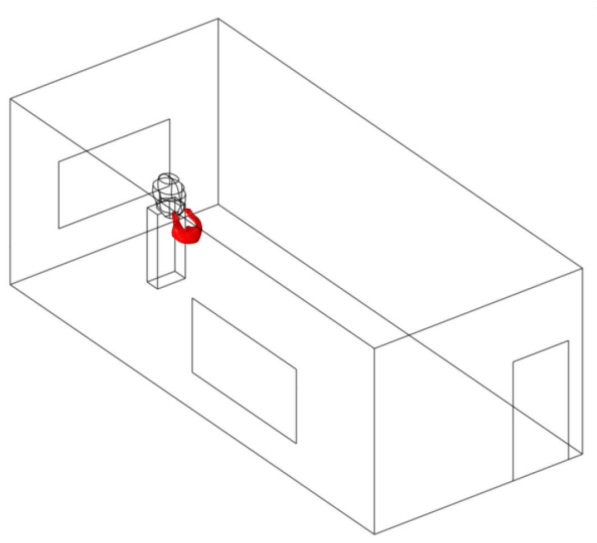

A

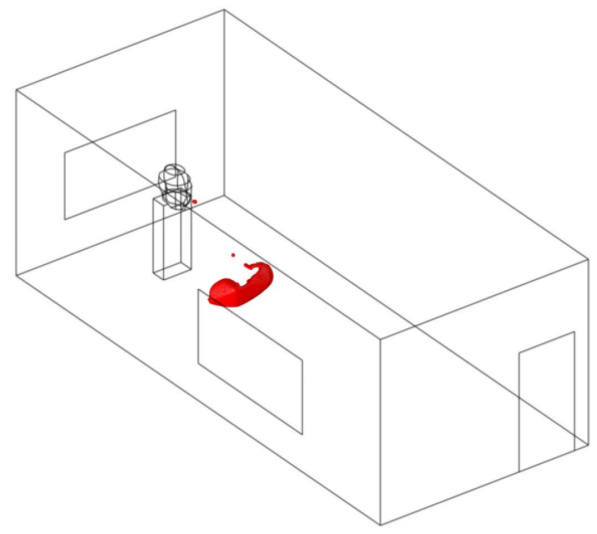

C

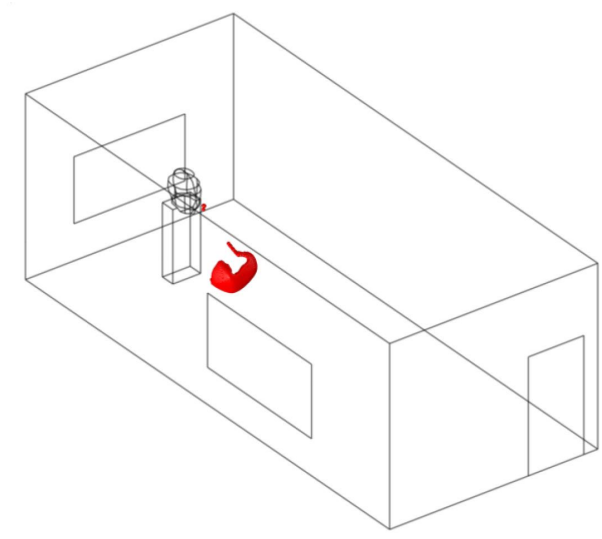

B

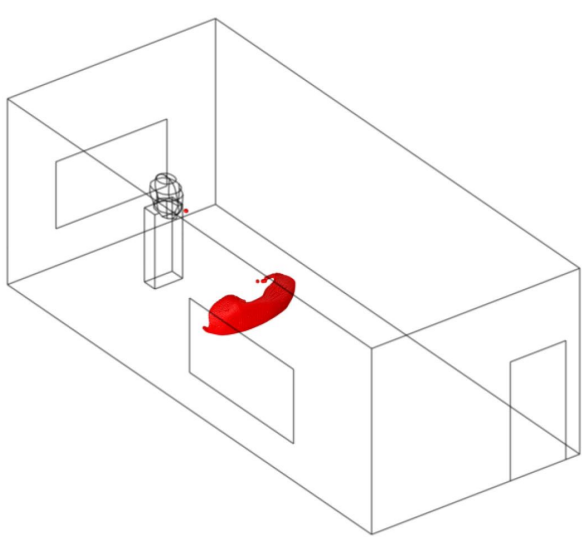

D

Figure 3. Droplets and aerosolized viral particles expelling from the body through coughing or sneezing and it is spreading to nearby surroundings. Spreading limits and pathways of the aerosolized viral particles and fine droplets suspended in the air in case when the person is in a place without air conditioning unit.

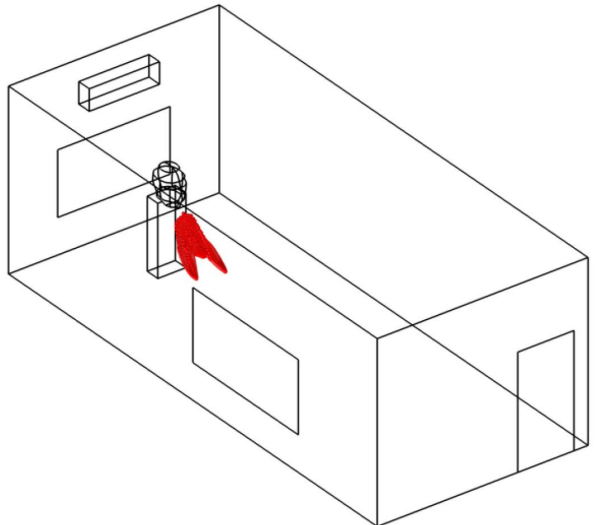

A

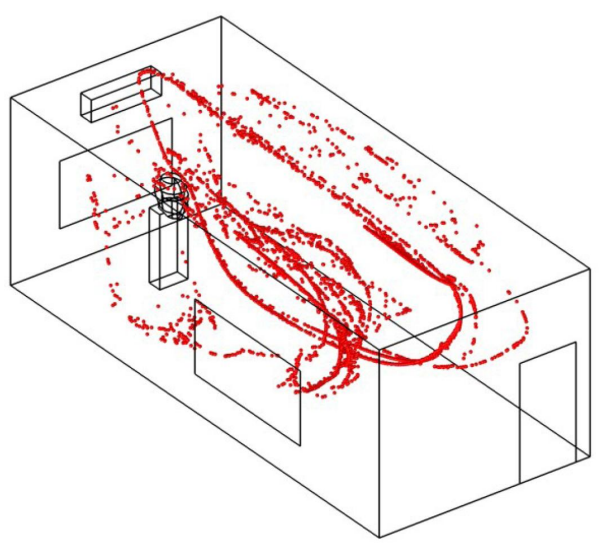

C

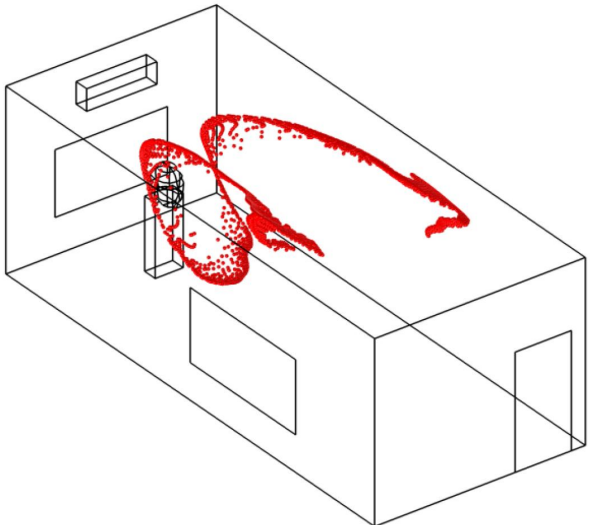

B

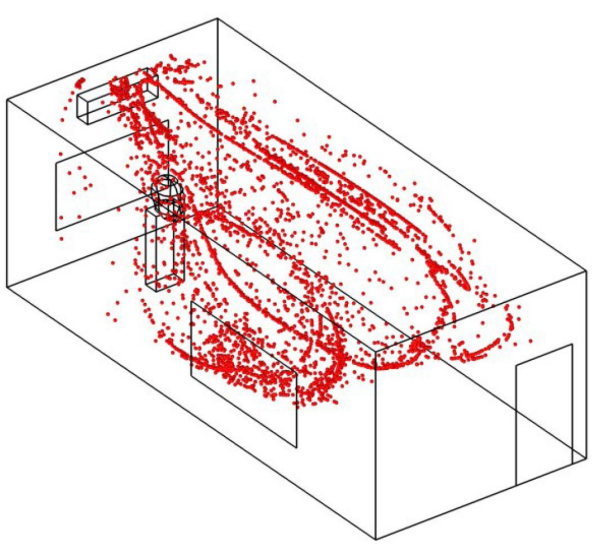

D

Figure 4. Droplets and aerosolized viral particles expelling from the body through coughing or sneezing and it is spreading to nearby surroundings. Spreading limits and pathways of the aerosolized viral particles and fine droplets 
suspended in the air in case when the person is in a place with air conditioning unit.

The results are clear illustrated that the use of air conditioning systems can increase the chances of spreading virus infection. The main problem is that many people admit to not being able to wear a mask all the time in the workplace. The use of air conditioning systems, as shown from the results of this work, can increase the chances of spreading virus infection. The easiest and least expensive way is to freshen the air by opening the windows to let fresh air in from outside. However, if this is difficult to do, air-sterilizing filters must be used in air conditioning systems to remove virus particles in the air.

\section{Conclusion}

COVID-19 spread faster with air-conditioning systems. Air circulation indoors such as using air conditioning units should be avoided in closed places. Existing ventilation systems should be expanded to include extraction and air filtration systems and/or germicidal, ultraviolet light. Also, opening a window can help bring in fresh air from the outside and disperse stale air inside, and that could help reduce the possibility of the spread of the virus particles in the closed place. Lastly, crowds of people in closed public places should be avoided.

\section{References}

1. Modes of transmission of virus causing COVID-19: implications for IPC precaution recommendations. World Health Organization 2020, Scientific brief, WHO reference number: WHO/2019-nCoV/Sci_Brief/Transmission_modes/2020.2, Available on https://www.who.int/news-room/commentaries/detail/modes-of-transmission-of-virus-causing-covid-19-implications-for-ipc-precautionrecommendations

2. In the time of Corona ... Beware of fans and air conditioners!. https://p.dw.com/p/3gGw7

3. Air Conditioning Systems Can Spread The Coronavirus, Study Suggests. https://www.wbur.org/hereandnow/2020/05/19/airconditioning-coronavirus

4. Can my fan or air conditioner spread coronavirus? Your COVID-19 questions answered. https://www.cbc.ca/news/health/fans-airconditioning-covid-questions-answered-1.5604437

5. Can Air Conditioning Transmit the Coronavirus?. https://www.nytimes.com/wirecutter/blog/air-conditioning-coronavirus/

6. How Much Should You Worry About Air Conditioning and COVID-19?. https://slate.com/technology/2020/07/covid19-air-conditioningcoronavirus-spread.html

7. Can COVID-19 Spread Faster in an Air Conditioned House?. https://health.mountsinai.org/blog/can-covid-19-spread-faster-in-an-airconditioned-house/

8. Can Air Conditioning Spread the Coronavirus?. https://www.theatlantic.com/health/archive/2020/06/is-air-conditioning-safepandemic/613438/

9. Dangers of COVID-19 aerosols are underestimated. https://p.dw.com/p/3f3rT

10. A terrifying fact ... the Corona virus is transmitted with fine dust particles!. https://p.dw.com/p/3gvUc

11. Fears SC, Klimstra WB, Duprex P, Hartman A, Weaver SC, Plante KS, et al. Persistence of severe acute respiratory syndrome coronavirus 2 in aerosol suspensions. Emerg Infect Dis. Vol.26, No.9, 2020, https://doi.org/10.3201/eid2609.201806

12. Dyani Lewis. Mounting evidence suggests that coronavirus can travel in airborne aerosols - but health advice has been slow to catch up. Nature 583, pp.510-513 (2020), https://doi.org/10.1038/d41586-020-02058-1

13. Lidia Morawska, Donald K Milton. It is Time to Address Airborne Transmission of COVID-19. Clinical Infectious Diseases, ciaa939, 06 July 2020, https://doi.org/10.1093/cid/ciaa939

14. Supplementary data of the paper in reference [222]. https://academic.oup.com/cid/advance-article/doi/10.1093/cid/ciaa939/5867798

15. Maher A.R. Sadiq Al-Baghdadi. Applications of Computational Fluid Dynamics (CFD) technology in engineering education. International Journal of Energy and Environment (IJEE) 2019, 10, pp.1-14. http://ijee.ieefoundation.org/vol10/issue1/IJEE_01_v10n1.pdf

16. Maher A.R. Sadiq Al-Baghdadi and Hashim R. Abdol-Hamid. CFD Applications in Energy and Environment. International Energy and Environment Foundation 2011, ISBN-13: 978-1466230651

\section{Keywords}

COVID-19; Spread; Air-Conditioning; Computational Fluid Dynamics; CFD; aerosolized viral particles; transmission via air; coronaviruses 